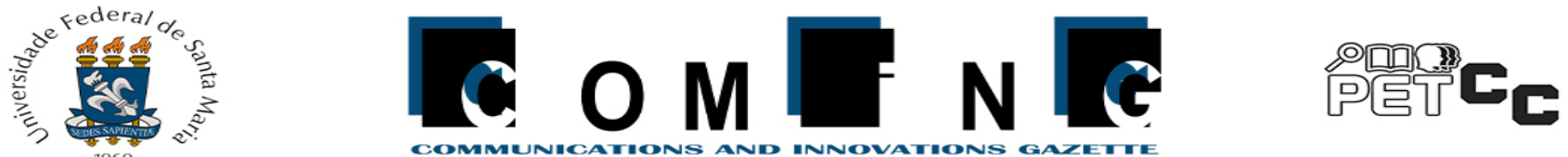

\section{Cursos de Extensão em Processamento de Alimentos: a Universidade inserida na Comunidade}

\author{
Ana Paula Nogueira Guimarães ${ }^{1}$, Mikaelly Veiga Borges ${ }^{1}$, \\ Adriana Régia Marques de Souza ${ }^{1}$, Miriam Fontes Araújo Silveira ${ }^{1}$ \\ ${ }^{1}$ Curso de Engenharia de Alimentos - Universidade Federal de Goiás (UFG) \\ Goiânia - GO - Brasil \\ \{anapaulanog99, mikaellyveiga\} ediscente.ufg.br, \\ adriana_regia_souza@ufg.br, miriamfas.ufg@gmail.com
}

\begin{abstract}
The Food Processing Extension Courses (CEPA) are aimed at different publics in society, which seek to improve their learning. They provide interaction between academia and society, promoting technical and citizen education for students. Thus, the objective was to promote extension courses in Food Processing, with an emphasis on good manufacturing practices and the stages of the food process. Nine courses were offered, with varied themes, by professionals in the field, assisted by students from the PET Engenharia de Alimentos group. The results of the participants' evaluations showed the success obtained in all the courses offered, highlighting the need for these for society.
\end{abstract}

Keywords: learning, society, experience, training .

Resumo. Os Cursos de Extensão em Processamento de Alimentos (CEPA) são direcionados a diversos públicos da sociedade, que buscam aperfeiçoar seu aprendizado, proporcionando interação com a universidade $e$ promovendo uma formação técnica e cidadã dos discentes. Dessa forma, objetivou-se promover cursos de extensão em Processamento de Alimentos, com ênfase nas boas práticas de fabricação e nas etapas do processo de alimentos. Foram ministrados nove cursos, com temas variados, por profissionais da área, auxiliados pelos alunos integrantes do Grupo PET Engenharia de Alimentos. Os resultados das avaliações dos participantes evidenciaram o exito obtido em todos os cursos oferecidos, ressaltando a necessidade desses para a sociedade.

Palavras-chave: aprendizado, sociedade, experiência, formação.

\section{Introdução}

A extensão é um dos três pilares que compõem a formação de uma Instituição de Ensino Superior (IES), juntamente com o ensino e a pesquisa, e tem como objetivo aproximar a academia da comunidade; por meio da disseminação dos conhecimentos científicos obtidos pela instituição de ensino com a sociedade. Trata-se da interação entre docentes, discentes e demais profissionais com a realidade e os problemas do cotidiano social ao 
seu redor, fornecendo a complementação da formação técnica dos discentes e a humanização dos indivíduos, contribuindo para o compartilhamento de experiências entre os dois ambientes [Oliveira e Nascimento-e-Silva 2019].

Ações desenvolvidas pelas instituições públicas podem ser de fundamental importância na inserção ou recolocação de pessoas em condição de vulnerabilidade social no mercado de trabalho, como por exemplo, cursos livres de qualificação profissional oferecidos à sociedade. Não só instituições públicas, como também iniciativas independentes, sem fins lucrativos, já apresentam propostas que visam promover maior inclusão social [Silva 2019].

Os cursos práticos são formações direcionadas a diversos públicos da sociedade que buscam aperfeiçoar o seu aprendizado. Aos jovens, os cursos proporcionam contato com o ambiente acadêmico e uma escolha acadêmica segura de acordo com seus interesses e perfil. Através dos cursos de extensão, também são atendidos profissionais, que obtêm em curto período de tempo maior aprendizado prático, além de aumentarem a rede de relacionamento ao interagirem com outros colegas e profissionais [Duarte 2014].

A produção de produtos alimentícios no Brasil vem crescendo de forma demasiada, principalmente de pequenas empresas e trabalhadores informais. Segundo o [IBGE 2020], o número de trabalhadores informais que atuavam no ramo alimentício em 2019 era de $41 \%$ e tal fato mostra que o processamento de alimentos vem crescendo e tem servido como fonte de renda para muitas famílias.

Dessa forma, objetivou-se promover cursos de extensão em Processamento de Alimentos, com ênfase nas boas práticas de fabricação e nas etapas do processo.

\section{Metodologia}

Os cursos ocorreram entre os anos de 2018 e 2019, no Setor de Engenharia de Alimentos da Escola de Agronomia (EA) da Universidade Federal de Goiás (UFG), sendo divulgados pelos meios digitais (e-mails, Instagram e WhatsApp). Para cada curso foram disponibilizadas 15 vagas, com as inscrições realizadas de forma online pelo Google Forms, através de um formulário. Essas ações ficaram sob a responsabilidade do Grupo PET Engenharia de Alimentos (PET EngAli). Cada curso teve a duração de quatro horas.

Ao iniciar os cursos, os participantes receberam materiais didáticos, com todas as etapas do processo detalhadas e a descrição das funções de cada ingrediente utilizado. Durante a realização do processamento dos produtos, o professor responsável pelo curso, auxiliado por alunos integrantes do Grupo PET EngAli, discutia todo o material, mostrando a importância das Boas Práticas de Fabricação (BPF) e o cuidado com cada etapa do processo, para obtenção de um produto seguro e de qualidade. Ao final da atividade, os produtos foram degustados e os participantes preencheram uma ficha (Figura 1), para avaliação do curso e definição do perfil. Todos receberam um certificado de participação ao final do curso. 


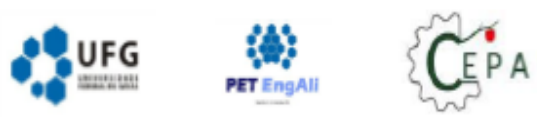

AVALIAC̣ÃO DE ATIVIDADE CEPA

Sua opinião é muito importante para que possamos melhorar sempre! Por este motivo, solicitamos sua colaboração no preenchimento deste questionário que visa obter um feedback sobre o minicurso realizado.

1. Idade:

2. Sexo:

$$
\text { () Feminino () Masculino }
$$

3. Grau de escolaridade:

4. Como você ficou sabendo desse minicurso: () Redes Sociais () Amigos

() Outros:

5. Atualmente, frequenta alguma instituição de ensino (fundamental, médio, técnico, superior)?

( ) Sim Qual? () Nào

6. Você já sabia produzir algum dos produtos ensinados no minicurso? Se sim, qual?

( ) $\operatorname{Sim}$

() Não

7. Usa/usou este meio de produção como fonte de renda?

() $\operatorname{Sim}$ () Não

8. Quanto à abordagem/exposição do conteúdo proposto:

( )Muito bom ( )Bom ( )Regular ( )Fraco
9. Quanto aos materiais utilizados durante a realização do minicurso:

( )Muito bom ( )Bom ( )Regular () Fraco

10. Suas expectativas sobre o minicurso foram atingidas? Caso sua resposta seja não, o que faltou para atingi-las?

() $\mathrm{Sim}$

( )Não

11. Recomendaria este minicurso para conhecidos?

() $\operatorname{Sim}$ () Talvez () Não

12. Você já participou de algum outro minicurso oferecido pelo grupo PET Engenharia de Alimentos? Se sim, qual?

( ) $\mathrm{Sim}$

() Não

13. Após participar do minicurso, você se sente apto(a) para reproduzir os produtos?

() $\operatorname{Sim}($ ) Talvez () Nào

14. Faria outro minicurso oferecido pelo grupo PET Engenharia de Alimentos? Se sim, qual minicurso seria atrativo para você? ( ) $\mathrm{Sim}$ () Não

Comentários e sugestôes:

AGRADECEMOS SUA ATENÇÃO:

Figura 1. Ficha de avaliação do curso de processamento e perfil dos participantes.

\section{Resultados e Discussão}

Foram ministrados nove cursos de processamento: compota e picles, queijos, pimenta, biscoito de queijo e pão de queijo, bolos veganos, confeitaria, bolos e dois cursos de panificação, um com fermentação com leveduras comerciais e o outro com fermentação natural. Houve um total de 117 participantes nos cursos.

O perfil dos participantes (Figura 2) indicou que a faixa etária da maioria dos inscritos $(51 \%)$ foi entre 31 e 50 anos, e o grau de escolaridade com ensino médio completo $(53 \%)$. A diversidade de faixa etária entre os participantes proporcionou uma maior troca de experiência, promovendo, assim, uma maior rede de conhecimento. 


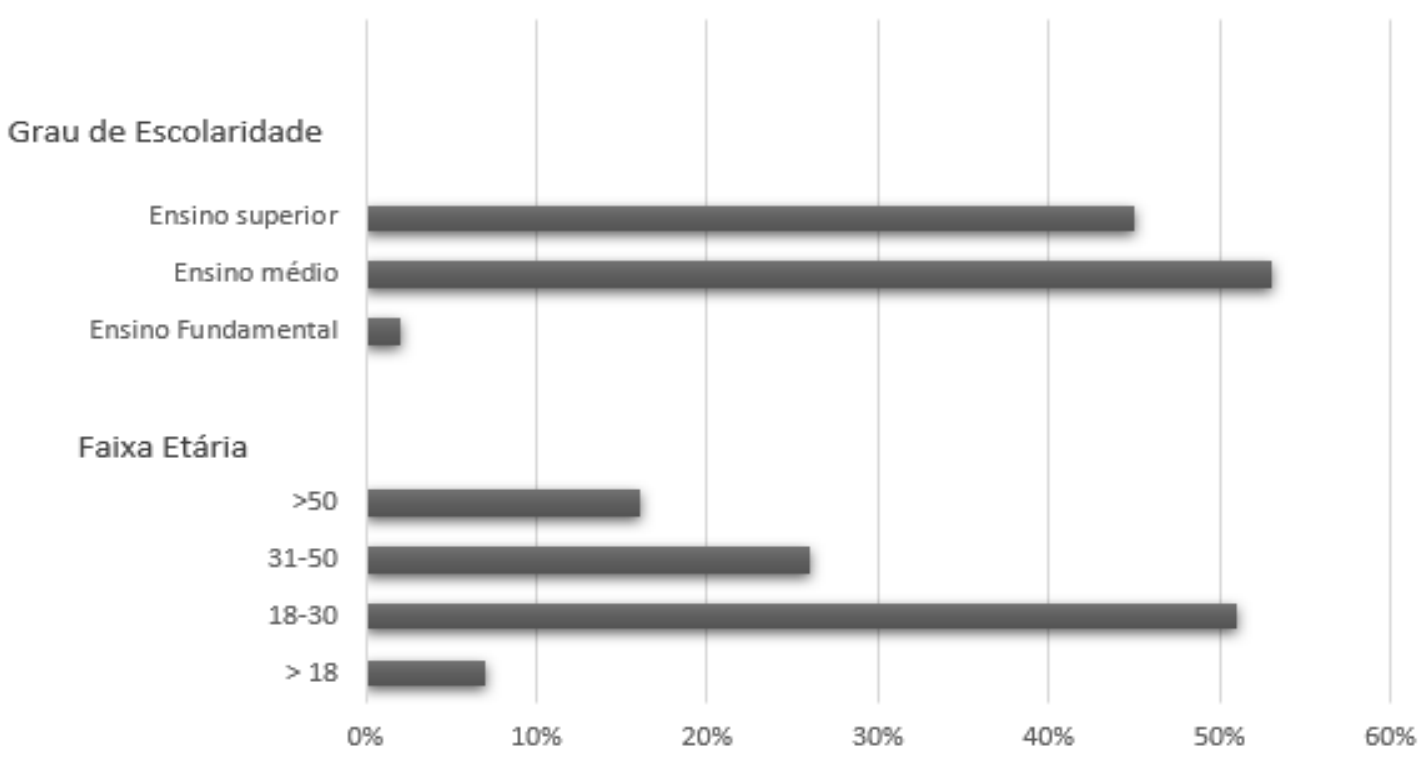

Figura 2- Perfil dos participantes (faixa etária e grau de escolaridade) dos cursos.

Através do feedback recebido dos participantes foi possível verificar se os cursos atenderam as expectativas e se houve um aproveitamento satisfatório.

O curso de Processamento de Compota e Picles contou com 11 participantes, que puderam aprender ou aprimorar seus conhecimentos em relação ao tema abordado. A compota ou fruta em calda é obtida do cozimento de frutas inteiras ou em pedaços, com ou sem sementes ou caroços, com ou sem casca, envasadas em lata ou vidro, praticamente cruas, cobertas com calda de açúcar [BRASIL 1978]. O picles é o vegetal fermentado ou acidificado, coberto com solução contendo vinagre (ácido acético) como o principal agente acidificante [Pérez-Díaz et al. 2015]. Todos os participantes declararam sentirem-se aptos a reproduzir o que aprenderam e tiveram suas expectativas atingidas, também recomendariam o curso e teriam interesse em realizar outros.

Quanto à abordagem do conteúdo e do material didático, $82 \%$ e $73 \%$ avaliaram como muito bons, respectivamente. Uma vez que o processamento desses produtos se baseia na conservação da fruta e/ou vegetal por um fluido concentrado de simples manipulação, necessita-se de certa precisão e cuidado na utilização dos ingredientes. Sendo assim, a didática utilizada pelo professor no curso e a qualidade dos materiais didáticos, facilitaram a produção e o entendimento dos conteúdos pelos participantes, favorecendo o aproveitamento e satisfação do curso para todos envolvidos.

De acordo com Mendes et al. (2020), os participantes dos cursos sobre boas práticas de fabricação, métodos de conservação, com o processamento de picles, e rotulagem de alimentos relataram que os conhecimentos adquiridos são muito importantes e ajudarão na melhoria da qualidade dos seus produtos, com grandes possibilidades de aumento nas vendas e na renda familiar. Esses cursos foram ministrados por professores da UFG e alunos do PET EngAli para produtores de alimentos de assentamentos rurais. 
No curso de Processamento de Queijos foram elaborados queijos do tipo prato, minas frescal, minas prensado e ricota. O queijo é o produto fresco ou maturado obtido por separação parcial do soro do leite ou leite reconstituído (integral, parcial ou totalmente desnatado), ou de soros lácteos, coagulados pela ação física do coalho, de enzimas específicas, de bactérias específicas, de ácidos orgânicos, isolados ou combinados, todos de qualidade apta para uso alimentar, com ou sem agregação de substâncias alimentícias [BRASIL 1996]. Os 12 participantes do curso consideraram a abordagem do conteúdo e os materiais utilizados muito bons, tendo as suas expectativas atingidas, disseram que recomendariam o curso para outras pessoas e teriam interesse em participar de outros cursos. Com relação a reproduzir o que aprenderam, 67\% declararam-se aptos. A produção de queijos requer etapas mais elaboradas e utilização de ingredientes específicos para ocorrer a coagulação, o que pode ser um fator de complexidade para a fabricação do produto, dificultando, em parte, seu processamento pelos participantes do curso.

Dentre os diversos tipos de temperos e condimentos, a pimenta é uma das mais utilizadas, já que melhora o sabor, o aroma e a cor das preparações [Poltronieri et al. 2006]. No curso de Processamento de Pimenta, os 18 participantes puderam elaborar pimenta desidratada, geleia e pimenta em conserva. Todos os participantes declararam que suas expectativas foram atingidas e que teriam interesse em realizar outros cursos. Quanto à abordagem do conteúdo e aos materiais didáticos, $83 \%$ e $72 \%$ julgaram como muito bons, respectivamente. O curso seria recomendado para outras pessoas por $94 \%$ dos participantes e $72 \%$ seriam capazes de reproduzir o que aprenderam. Os resultados demonstram que o processamento de pimenta é fácil e prático, mas, como todo produto artesanal, exige muito cuidado na produção e alguns materiais específicos, para se obter produtos seguros e de boa qualidade.

Quitandas para os mineiros é tudo que é feito em casa e servido com café, como queijos, broas, sequilhos, biscoitos e bolos [Silva 2016]. O pão de queijo e o biscoito de queijo são quitandas bem famosas e amplamente consumidas em todo país. São produtos de panificação que apresentam elevada fonte de energia, com menor valor calórico, alto teor de carboidratos e isento de glúten na sua formulação [Philippi 2015]. O curso de Processamento de Pão de Queijo e Biscoito de Queijo contou com 15 participantes, que puderam aprender sobre a função de cada ingrediente e, também, sobre o processamento desses produtos sem a utilização do escaldamento, que foi substituído pelo amido modificado. Dos integrantes, $60 \%$ afirmaram que a abordagem do conteúdo foi muito boa e $40 \%$ que foi boa; $80 \%$ avaliaram o material didático como "muito bom".

Com relação à estarem aptos para reproduzir os produtos elaborados, 53\% declararam aptos e $47 \%$ talvez. A maior dificuldade dos participantes para reproduzir o processamento desses produtos, provavelmente, foi que a abordagem desse assunto se deu a nível industrial. Foram utilizados ingredientes e equipamentos usados em indústrias, o que poderá dificultar a produção dessas quitandas por métodos caseiros e/ou artesanais. Contudo, o curso atingiu as expectativas de $93 \%$ dos presentes, afirmando, também, que recomendariam o curso a outras pessoas, dado a eficiência da elaboração desses produtos, mesmo com um aspecto mais industrial. Ademais, todos os participantes relataram que teriam interesse em realizar outros cursos. 
O crescimento do público vegano evidencia um nicho de mercado que demanda adaptações às técnicas e insumos clássicos, além da importância de conhecer esse novo público e suas respectivas necessidades [Correia 2019]. Nesse contexto, foi oferecido um curso de Processamento de Bolos Veganos, com 11 participantes, no qual foram produzidos bolos de cenoura, banana e cacau. Dos participantes, 91\% julgaram a abordagem do conteúdo como "muito bom" ou "bom" e recomendariam o curso aos amigos. Todos os participantes relataram que o curso atendeu suas expectativas e que fariam outros cursos. Quanto à aptidão em reproduzir os produtos processados, $73 \%$ julgaram-se aptos, $18 \%$ talvez e $9 \%$ relataram que não conseguiriam. A dificuldade em reproduzir os produtos pode ocorrer devido a algumas barreiras ainda encontradas pelo público vegano, como preço elevado, distribuição restrita e falta de opções de produtos e marcas [Queiroz et al. 2018], além da complexidade da substituição dos ingredientes de origem animal na fabricação desse tipo de produto.

Conforme reportagem da EMATER - DF (2019), a empresária Carla Burin e sua família têm alcançado sucesso com o processamento e a comercialização de salgados veganos no atacado, com um crescimento nas vendas acima de $200 \%$ no último ano. A ideia surgiu ao perceber a falta de opções para consumidores desta linha de produtos, o que mostra a importância do empreendedorismo na área de processamento de alimentos.

$\mathrm{O}$ curso de Processamento de Produtos de Confeitaria atendeu à expectativa de todos os 15 participantes, afirmando, também, que recomendariam e fariam outros cursos. De acordo com a Resolução CNNPA no 12/78 "produtos de confeitaria são aqueles obtidos por cocção adequada de massa preparada com farinhas, amidos, féculas e outras substâncias alimentícias, doces ou salgados, recheados ou não" [BRASIL 1978]. Dessa forma, no curso foram elaborados patê sucrée, sonho e brownie; sendo que $80 \%$ dos participantes avaliaram os conteúdos abordados e os materiais didáticos como muito bons. Por outro lado, $20 \%$ dos participantes declararam que algumas etapas do processamento não ficaram claras, quanto ao entendimento.

Dos participantes, $66 \%$ julgaram-se aptos para reproduzir esses produtos, porém, para os demais, provavelmente, por serem produtos bastante elaborados, que devem ser produzidos cuidadosamente, causa receio na produção futura desses alimentos. A precisão no preparo, o conhecimento das técnicas e dos ingredientes utilizados são fatores essenciais para um resultado satisfatório na confeitaria [Galves e Eleutério 2014].

Os bolos têm ocupado posição relevante entre os produtos panificados, perdendo apenas para o pão [Gohara et al. 2014]. Trata-se de um produto obtido da mistura homogeneizada e cozimento da massa preparada com farinha, gordura, ovos, açúcar, fermento e um líquido, sendo que, se alteradas as proporções destes ingredientes, podese produzir diferentes preparações [Kovesi et al. 2007]. No curso de Processamento de Bolos foram produzidos bolo de cenoura, americano, banana com farinha de rosca, fubá de massa cozida e pão de mel.

Dos 12 participantes, $83 \%$ e $92 \%$ consideraram a abordagem do conteúdo e os materiais didáticos muito bons, respectivamente, e $67 \%$ julgaram-se aptos a reproduzir os produtos, provavelmente, os demais participantes sentiram dificuldades por se tratar de bolos mais elaborados e diferentes dos habituais, normalmente encontrados em padarias, e que demandam maior tempo de preparo e cuidados mais minuciosos. Apesar disso, todos os participantes alegaram que suas expectativas foram atingidas, e que além 
de recomendar o curso para parentes e amigos, também fariam outros cursos de processamento de alimentos.

A panificação é um dos seis maiores segmentos industriais do Brasil com participação de $7 \%$ do total da indústria de transformação e $36,2 \%$ do setor de produtos alimentícios. As empresas do segmento registraram em 2018 um crescimento de 2,8\%, e o faturamento chegou a $\mathrm{R} \$ 92,6$ bilhões [Propan 2019]. Foram realizados dois cursos de Panificação, um com fermentação com leveduras comerciais e o outro com fermentação natural.

Na Figura 3 estão apresentados os resultados das avaliações dos dois cursos de panificação. Observa-se que todos os participantes sentiram-se satisfeitos com a abordagem dos conteúdos, fariam outros cursos e recomendariam a outras pessoas. Apesar de a fermentação natural ser um processo mais longo, devido ao tempo necessário para a fermentação da massa e preparo do levain, os participantes conseguiram compreender a influência de cada etapa do processamento e a função dos ingredientes, sendo que $92 \%$ das pessoas julgaram-se aptas a produzirem os produtos de fermentação natural e $73 \%$ aptas a produzirem produtos de fermentação com leveduras comerciais.

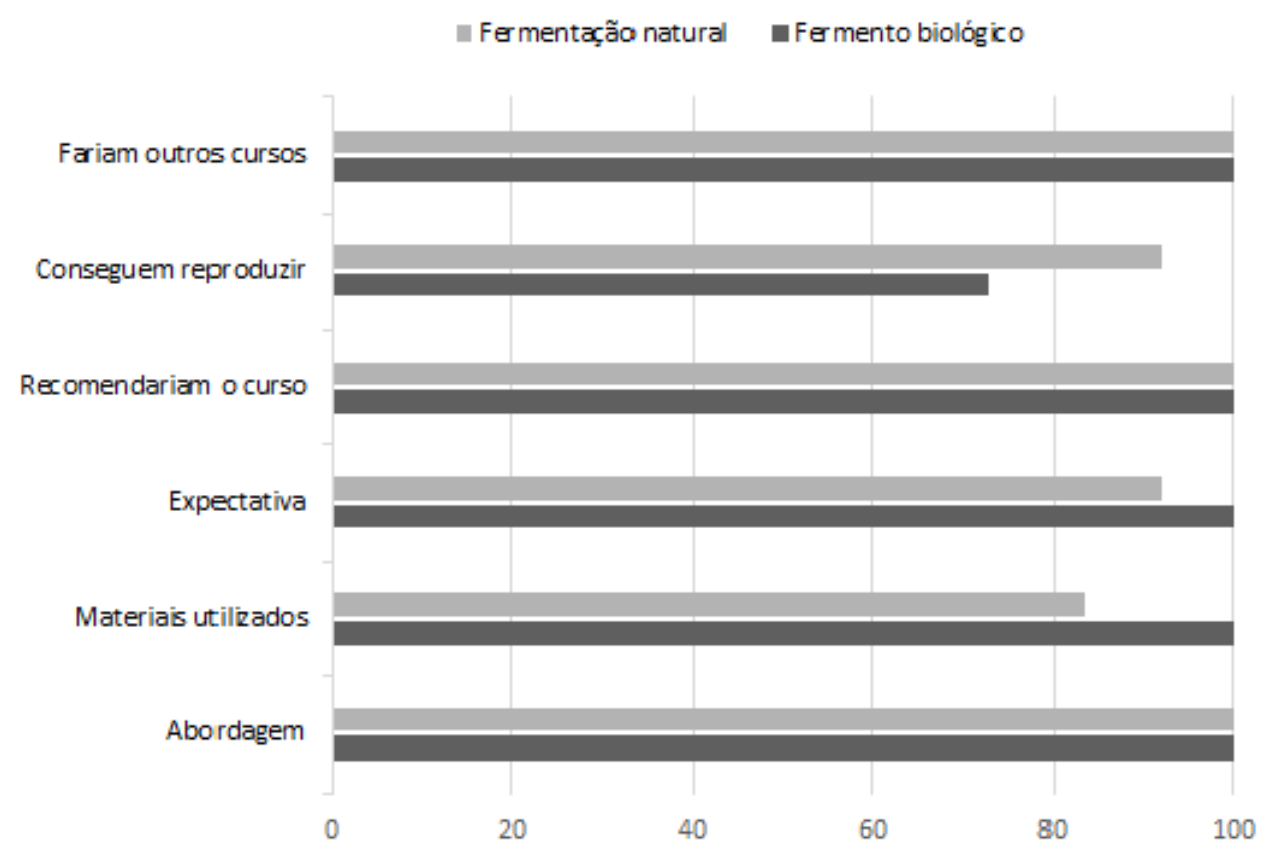

Figura 3. Cursos de panificação com fermentação natural e com leveduras comerciais.

Os resultados das avaliações dos participantes evidenciaram o êxito obtido em todos os cursos ministrados, o que estimula os organizadores, professores e alunos do Grupo PET Engenharia de Alimentos, a oferecerem outros cursos de extensão. Também, Miranda et al. (2017) relataram ótimos resultados no curso de capacitação em manipulação e processamento de alimentos, ministrado para mulheres de comunidades da região sudeste do município de Goiânia-GO. 
A realização de ações de extensão desta natureza demonstra relevância, pois capacita pessoas da comunidade, interessadas em processamento de alimentos, tanto para fins comerciais, como fonte de renda, quanto para consumo familiar, além de contribuir para a formação global dos estudantes envolvidos. De acordo com Figueiredo e Figueirêdo (2010), cursos de extensão em processamento de leite, de hortaliças e de frutas, ministrados para pequenos produtores do sul da Bahia, apresentaram saldo positivo, pois o público treinado já conseguiu montar suas unidades agroindustriais. Porém, consideraram que o mais importante foi proporcionar o estreitamento das relações entre professores/alunos da universidade e produtores através da transferência de conhecimentos e tecnologias, fortalecendo o segmento agroindustrial e promovendo uma melhor qualidade de vida para os envolvidos na atividade.

\section{Conclusão}

Os cursos de extensão em Processamento de Alimentos oferecidos tiveram grande aceitabilidade e receptividade dos participantes, mostrando a importância da oferta de cursos para capacitação da comunidade externa às Instituições de Ensino. É notório que os cursos de extensão são necessários, tanto para disseminar e agregar conhecimentos aos participantes, quanto para auxiliar na consolidação do aprendizado dos estudantes universitários e, dessa forma, contribuir para a interação entre universidade e sociedade.

\section{Agradecimentos}

Ao Ministério da Educação (MEC) e ao Fundo Nacional de Desenvolvimento da Educação (FNDE), pelas bolsas concedidas ao Programa de Educação Tutorial.

\section{Referências}

BRASIL (1996) Ministério da Agricultura, Pecuária e Abastecimento (MAPA). Portaria MAPA - 146, de 07/03/1996. São Paulo. https://www .defesa.agricultura.sp.gov.br/legislacoes/portaria-mapa-146-de-07-031996,669.html. [Online; acessado em 26-07- 2020]

BRASIL (1978) Ministério da Saúde. Anvisa. Resolução CNNPA nº 12, de 24 de julho.

Correia, I. S. (2019) Relatório de estágio supervisionado obrigatório realizado em uma padaria artesanal. [s.l: s.n.]. Universidade Federal Rural de Pernambuco Departamento de tecnologia rural curso de bacharelado em gastronomia. Recife, PE.

Duarte, J. S. (2014) As contribuições da extensão universitária para o processo de aprendizagem, a prática da cidadania e o exercício profissional. Brasília-DF. [s.l: s.n.].

EMATER-DF. (2019) Empresa de Assistência Técnica e Extensão Rural do Distrito Federal. Salgados veganos garantem renda à família de produtores. https://www.emater.df.gov.br.html [Online; acessado em 20-12-2020]. 
Figueiredo, A. F. R. Figueirêdo, V. R. (2010). Treinamento agroindustrial de pequenos produtores do sul da Bahia. Revista Eletrônica de Extensão, v. 7, n. 10, p. 150-157.

Galves, M. de C. P; Eleutério, H. (2014) Técnicas de Confeitaria. $1^{a}$ edição. Editora Érica.

Gohara A, A. K.; Souza, A. H. P. Zanqui, A. B.; Souza, N. E.; Visentainer, J. V.; Matsushita , M.(2014). Chemometric tools applied to the development and proximal and sensory characterization of chocolate cakes containing chia and azuki. Acta Scientiarum Technology, v. 36, n. 3, p. 537-543.

IBGE - INSTITUTO BRASILEIRO DE GEOGRAFIA E ESTATÍSTICA. (2020). Pesquisa Nacional por Amostra de Domicílios Contínua (PNAD Contínua). Rio de Janeiro.

Kovesi , B. Siffert , C. Crema, C. Martinoli, G. (2007). 400 g: técnicas de cozinha. São Paulo: Companhia Editora Nacional. 576 p.

Mendes, M. F. C. et al. (2020) Capacitação de produtores de alimentos de assentamentos rurais do estado de Goiás. In: SILVA-MATOS, R. R. S. et al. Resultados econômicos e de sustentabilidade nos sistemas nas ciências agrárias. 1 ed. Ponta Grossa - PR: Atena, p. 16-23.

Miranda, B. M.; Silveira, M. F. A.; Souza, A. R. M. (2017). Capacitação em manipulação e processamento de alimentos para fins comerciais. Revista Extensão, v. 11, n.1, p. 104-110.

Oliveira, E. S. Nascimento-e-Silva, D. (2019). A extensão como suprimento de necessidades: reflexões sobre as relações das instituições de ensino superior e da extensão com o macroambiente. Expressa Extensão, v. 24, n. 2, p. 88-95.

Pérez-Díaz, I. M., et al. (2015). Fermented and acidified vegetables. In: DOWNES, P., ITO, K. Compendium of Methods for the Microbiological Examination of Foods. 4 ed. American Public Health Association, Washington, DC, p. 521 - 532.

Philippi, S. T. (2015). Tabela de Composição de Alimentos. Suporte para decisão nutricional. 5 edição. Editora Manole Ltda.

Poltronieri, M. C. et al. (2006). Tratos culturais em pimenta de cheiro (Capsicum chinense Jacquin). Belém: Embrapa Amazônia Oriental, 4 p.

Propan. (2019) Perfil da Panificação: Desempenho das Panificadoras e Confeitarias Brasileiras em 2018. http://www.propan.com.br/?pagina=indicadores. [Online; acessado em 27-10- 2020].

QUEIROZ, C. A.; SOLIGUETTI, D. F. G.; MORETTI, S. L. A. (2018). As principais dificuldades para vegetarianos se tornarem veganos: um estudo com o consumidor brasileiro. Alimentação, Nutrição \& Saúde, v. 13, n. 3, p. 535-554.

SILVA, A. (2016) O que é quitanda para o mineiro. https://www .conhecaminas.com/2016/02/o-que-e-quitanda-para-o-mineiro.html. [Online; acessado em 27-10- 2020].

SILVA, E. B. (2019). Superação na Cozinha: Curso de capacitação em Gastronomia para pessoas em condição de vulnerabilidade social. Departamento de Economia 
Doméstica, Laboratório de Alimentos e Bebidas - Universidade Federal Rural do Rio de Janeiro (UFRRJ). Seropédica. 